\title{
Interference Simulation and Measurements for a Deployed 4G-WiMAX Network In an Urban Sub-Saharan African Environment
}

\author{
E.T. Tchao \\ Department of Electrical \\ Electronic Eng \\ Kwame Nkrumah Univ. \\ of Science and Tech \\ Kumasi, Ghana
}

\author{
W.K. Ofosu \\ Department of Electrical \\ Engineering Technology \\ Penn State Wilkes-Barre \\ USA.
}

\author{
K. Diawuo \\ Department of Electrical \\ Electronic Eng \\ Kwame Nkrumah Univ. \\ of Science and Tech \\ Kumasi, Ghana
}

\author{
E. Affum \\ Department of Electrical \\ Electronic Eng \\ Kwame Nkrumah Univ. \\ of Science and Tech \\ Kumasi, Ghana
}

\author{
Kwame Agyekum \\ Department of Electrical \\ Electronic Eng \\ Kwame Nkrumah Univ. \\ of Science and Tech \\ Kumasi, Ghana
}

\begin{abstract}
WiMAX is a popular broadband solution with diverse applications. With several advantages such as low cost applications and last mile solution for broadband wireless access, WiMAX will no doubt help bridge the ever increasing digital divide in many SubSaharan African countries. Many countries Sub of the Sahara have recently started deploying WiMAX to offer subscribers affordable broadband internet service. Because of the peculiar conditions in Sub- Sahara Africa, critical design and optimization techniques will be vital in making WiMAX networks deliver as expected by subscribers. In order to achieve maximum capacity while maintaining an acceptable grade of service and higher network performance of these newly deployed networks, the effect of interference should be catered for. This paper presents Network simulations results of a newly deployed 4G-WiMAX network deployed in Accra and Tema municipality, Ghana. A Monte Carlo simulation has been used to study the total interference in the network and the results presented. Finally the Network performance is evaluated through measurements of Received Total Wideband Power (RTWP) and outdoor interference and the results compared.
\end{abstract}

\section{Keywords:}

4G-WiMAX, Network planning, Interference, Performance, Field measurementsifx

\section{INTRODUCTION}

Broadband internet access helps to build, a people-centered, inclusive and development-oriented Information and knowledge Society, where everyone can create, access, utilize and share information and knowledge; enabling individuals, communities and peoples to achieve their full potential in promoting sustainable development and improving their quality of life [1]. Broadband internet is quite expensive in Africa and as such there is a need to find an affordable technology which will provide a platform for the least privileged to have access to broadband internet access even at a distance of many kilometers from his home [2].
Presently, the demand of worldwide interoperability for microwave access (WiMAX) are increasing numerously worldwide for commercial communication because WiMAX provides high speed connectivity and easy access to networks and long operating range with high data rates [3] and as such, WiMAX offers a realistic opportunity for subscribers in Sub- Sahara Africa to have access to cheap and a seemingly faultless broadband internet access.

This increase in demand and explosive growth in data traffic has put much pressure on network operators [4]. It therefore implies that, the design and optimization of WiMAX networks will play a vital role in delivering high quality services at affordable prices. The design and optimization techniques of WiMAX networks significantly differ from the techniques used for planning other networks. It has been established in literature that coverage or capacity of radio communication systems cannot be planned individually because of the interference limited nature of the airinterface [5].

Estimation of interference is an important step in determining the coverage or capacity of a cell. The amount of interference seen at each receiver location is highly dependent on transmit power, which in turn depend on the closed loop power control in uplink and downlink [6]. It is possible to estimate the interference of a cell fairly accurately using static simulation when the location information of transmitters and receivers are available. Even though stochastic models using statistical distribution of transmit powers and interferences cannot take into account all the unique characteristics of the WiMAX network simultaneously, they are useful in estimating performance figures during radio network planning for WiMAX systems.

\section{INTERFERENCE SCENARIOS}

WiMAX systems are designed to maximize coverage and as such Base stations are optimally placed to augment coverage problems. The network under study covers $55 \mathrm{sq} \mathrm{km}$ in the central parts of Accra and Tema. There are 11 Base stations (BS) and about 535 customer premise equipments (CPE) in the network as shown in Figure 1. The Base stations are located throughout 
the Network area to prevent coverage holes caused by shadowing of the radio signal due to buildings, foliage, etc

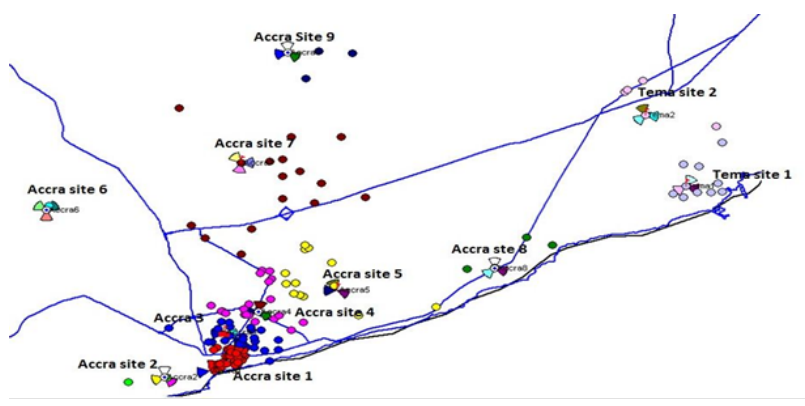

Fig. 1. Distribution of CPE in the Deployed Network

The network in Figure 1 is a newly deployed network in a dense urban Sub-Saharan African environment and as such there are bound to be interference in the system. Possible interference scenarios that are bound to occur in the deployed network have been shown in Figure 2 and Table 1.

The interference Scenarios that are bound to be encountered in the network scenarios depend upon the characteristics of Base Stations (BS) and Mobile Stations (MS). In scenario 1, the effect of interference between interferer system and victim system is related with their respective locations. In the second scenario, when the MS in downlink is very close to the MS of interferer system in uplink, the MS of interferer system in uplink interferes with the MS of victim system.

Table 1. Possible interference scenarios in the Network

\begin{tabular}{|c|c|c|}
\hline Scenario & Interference Path & Direction \\
\hline 1 & Base station to Mobile Station & Downlink to Downlink \\
\hline 2 & Mobile Station to Mobile Station & Uplink to Downlink \\
\hline 3 & Mobile Station to Base station & Uplink to Uplink \\
\hline 4 & Base station to Base station & Downlink to Uplink \\
\hline
\end{tabular}

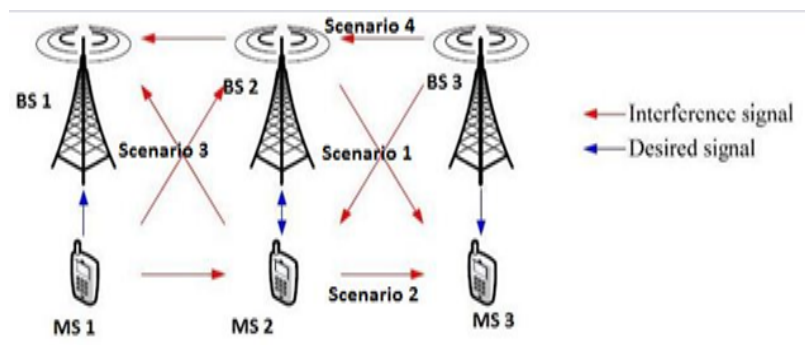

Fig. 2. Possible interference scenarios in the Network

Because the transmitter power of the MS is smaller than that of the BS and the relative mobility of the MS can contribute to a transient nature to the interference, other studies have concluded that this interference level is negligible when considered across a network [7]. The worst case in these two scenarios occurs with a low probability [8].

The fourth scenario shown in Figure 3 is the most severe. The reason is that Base stations in the network have been located at high positions for maximum coverage, leading to a high probability that the propagation loss between BS of victim system and BS of interferer system is low [8] [9]. In order to fully understand the impact of interference on the deployed network, this paper uses Monte Carlo simulation to describe the total interference scenario 4 poses to the network.

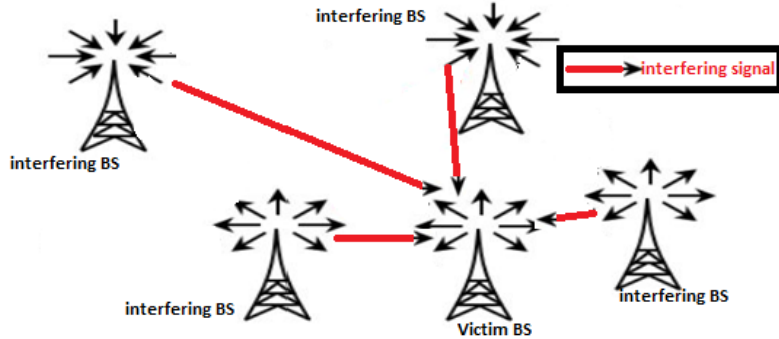

Fig. 3. Multiple Base Station to Base Station interferers

\section{COVERAGE PREDICTION}

The coverage prediction for the deployed network simulation is based on a realistic distribution of BS and CPEs in the network as shown in Figure 1 and the network parameters in Table 2.

Table 2. Simulation parameters

\begin{tabular}{|l|c|}
\hline Resource frequency & $2.5-2.53 \mathrm{GHz}$ \\
\hline Channel Bandwidth & $10 \mathrm{MHz}$ \\
\hline Fast Fourier Transform (FFT) Size & 1024 \\
\hline Subcarrier spacing & $10.93 \mathrm{kHz}$ \\
\hline Useful symbol time & $91.4 \mu \mathrm{s}$ \\
\hline Guard time & $11.4 \mu \mathrm{s}$ \\
\hline OFDMA symbol time & $102.8 \mu \mathrm{s}$ \\
\hline Modulation & QPSK, $16-\mathrm{QAM}, 64-\mathrm{QAM}$ \\
\hline Antenna frequency Range & $2.3-2.7 \mathrm{GHz}$ \\
\hline VSWR & $\leq 1.5$ \\
\hline Input Impedance & $50 \Omega$ \\
\hline Gain & $18 \mathrm{dBi}$ \\
\hline Horizontal Beamwidth (3dB) & $60^{\circ}$ \\
\hline Vertical Beamwidth (3dB) & $7^{\circ}$ \\
\hline Electrical downtilt & $2^{\circ}$ \\
\hline Maximum power & $250 \mathrm{~W}$ \\
\hline Antenna height & $38 \mathrm{~m}$ \\
\hline
\end{tabular}

The Received Signal strength indicator (RSSI) simulation results for the network have been summarized in Table 3 .

Table 3. RSSI values for CPE

\begin{tabular}{|c|c|l|l|l|l|}
\hline $\begin{array}{l}\text { Antenna } \\
\text { config. }\end{array}$ & SS type & $\begin{array}{l}\text { DL } \\
\text { traffic } \\
\text { CINR } \\
(\mathrm{dB})\end{array}$ & $\begin{array}{l}\text { DL traf- } \\
\text { fic RSSI } \\
(\mathrm{dBm})\end{array}$ & $\begin{array}{l}\text { Cell } \\
\text { Radius } \\
(\mathrm{Km})\end{array}$ & $\begin{array}{l}\text { Site-Site } \\
\text { Distance } \\
(\mathrm{Km})\end{array}$ \\
\hline 2T2R & USB & 3 & -87 & 0.44 & 0.7 \\
& Indoor & 3 & -91 & 0.75 & 1.1 \\
& Outdoor CPE & 3 & -92 & 2.99 & 4.5 \\
\hline 4T4R & USB & 3 & -87 & 0.54 & 0.8 \\
& Indoor CPE & 3 & -91 & 0.91 & 1.4 \\
& Outdoor CPE & 3 & -92 & 3.61 & 5.4 \\
\hline
\end{tabular}

Based on the RSSI simulation results and the distribution of CPE in the network in Table 3 and Figure 1 respectively, a 4 Transmit 4 Receive antenna configuration which gives better RSSI values over 2 Transmit 2 Receive configuration was used in the final coverage simulation using Genex-Unet to give the final coverage plan as shown in Figure 4.

The 4T4R configuration gives a $3 \mathrm{~dB}$ increase in downlink/uplink coverage and higher throughput which reduces the number of base station sites in certain areas and lower total cost of ownership. Since 4T4R configuration simulation results in Table 3 gives an enhanced coverage capabilities and capacity, 11 base stations with a 32 sector antenna configuration will give 


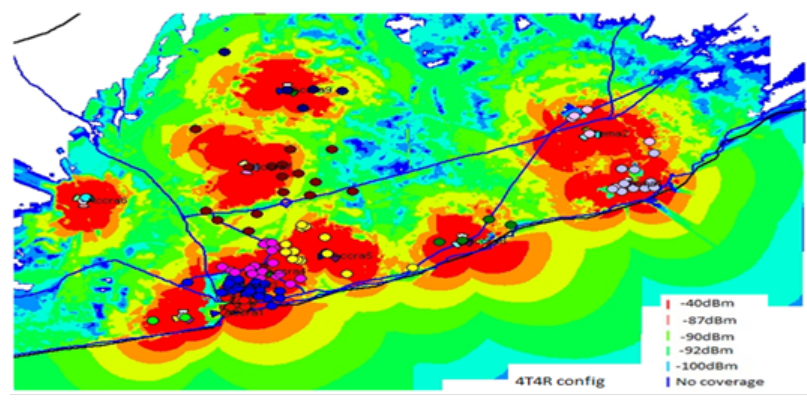

Fig. 4. Final coverage plan using $4 T 4 R$ antenna configuration

coverage to the entire Accra and Tema Network with simulated RSSI of $-92 \mathrm{dBm}$ as shown in Figure 4.

\section{INTERFERENCE SIMULATION}

The interference simulation was based on a Monte Carlo simulation approach. A total of 5000 draws have been made for calculating the total interference. The inter-site distances from the deployed WiMAX network in the Accra and Tema municipality is summarized in Table 4he mean power from the Base stations with their respective standard deviation used for the simulation is given in Table 5 .

Table 4. The inter-site distances of $\mathrm{BS}$ in the deployed WiMAX network

\begin{tabular}{|c|c|c|}
\hline Site A & Site B & Inter- site distances $(\mathrm{km})$ \\
\hline Accra site 1 & Accra site 2 & 1.938 \\
\hline Accra site 1 & Accra site 3 & 1.072 \\
\hline Accra site 1 & Accra site 4 & 2.423 \\
\hline Accra site 4 & Accra site 5 & 1.563 \\
\hline Accra site 5 & Accra site 6 & 6.2 \\
\hline Accra site 5 & Accra site 8 & 7.542 \\
\hline Accra site 5 & Accra site 7 & 8.59 \\
\hline Accra site 7 & Accra site 9 & 5.342 \\
\hline Accra site 6 & Accra site 7 & 5.734 \\
\hline Tema site 1 & Tema site 2 & 4.494 \\
\hline Tema site 1 & Accra site 8 & 23.33 \\
\hline
\end{tabular}

Table 5. Mean power and Standard Deviation

\begin{tabular}{|l|l|l|}
\hline Signal & $\begin{array}{l}\text { Simulated Mean } \\
\text { power }(\mathrm{dBm})\end{array}$ & $\begin{array}{l}\text { Standard Devia- } \\
\text { tion }\end{array}$ \\
\hline Wanted signal & -80 & 8 \\
\hline Interfering Base Station 1 & -82 & 7 \\
\hline Interfering Base Station 2 & -89 & 6 \\
\hline Interfering Base Station 3 & -87 & 8 \\
\hline Interfering Base Station 4 & -90 & 10 \\
\hline Interfering Base Station 5 & -92 & 7 \\
\hline
\end{tabular}

From the Final coverage plan in Figure 4, if there is bound to be any interference from neighboring BS, it is most likely to be high around Accra sites 1, 2, 3, 4, 5, 8 and Tema sites 1 and 2 because of their shorter inter- site distances. The BS to BS interference scenario which has been simulated models the wanted signal from one base stations and five interfering BS arriving at the victim?s receiver.

$$
I_{\text {tot }}=10 \log \left(i_{1}+i_{2}+i_{3}+\ldots+i_{n}\right)
$$

Where,

$I_{(t o t)}=$ Total interference

$i_{1}=$ first interfering Base Station

$i_{n}=$ the $n_{t h}$ interfering Base Station
A simple Monte Carlo simulation where randomly drawn values for actual signal and interfering signals from their corresponding Gaussian distributions and. Equation 1 was used to estimate the total interference to the victim Base station's receiver and the results shown in Figures 5 and 6.

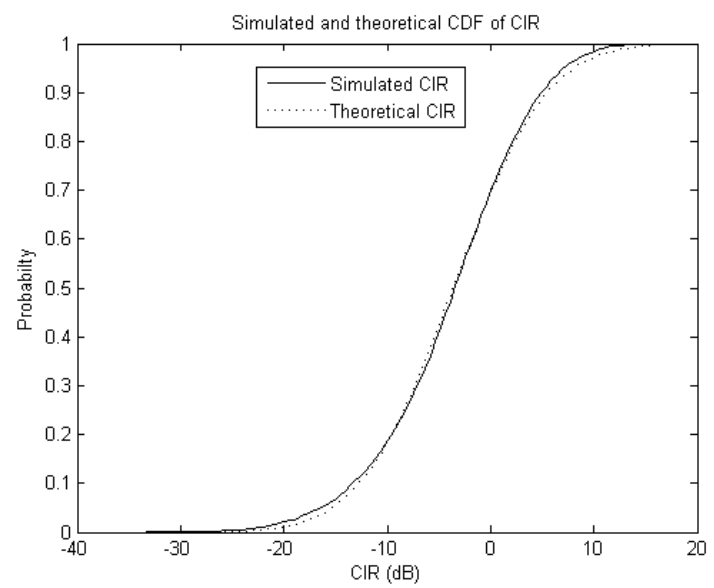

Fig. 5. Simulated and theoretical CDF of CIR

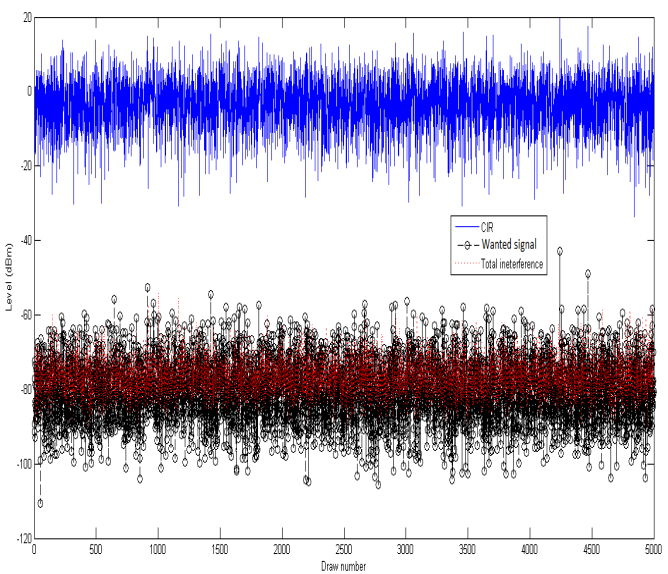

Fig. 6. Effect of interfering signals on the wanted Signal

From the results in Figure 7, the simulated mean CIR was $3.3195 \mathrm{~dB}$ with a standard deviation of 6.9622 . The mean simulated total interference from the 5 Base Stations (Itot) to the victim?s receiver was $-76.5364 \mathrm{dBm}$ with a standard deviation of 4.73 .

This value is very significant and can cause degradation to the link quality affecting the overall network performance and as such, network Optimization schemes are needed to help minimize the effect of interference

\section{FIELD MEASUREMENT}

In order to achieve the objectives of planning to provide coverage as required and predicted during the simulation stage and reducing channel interference levels as predicted for maintaining good quality of service in the network, it was relevant to carry out field measurement to relate the simulation results to practical scenarios. Real world measurement was carried out to determine the interference on the Base Stations at four selected 


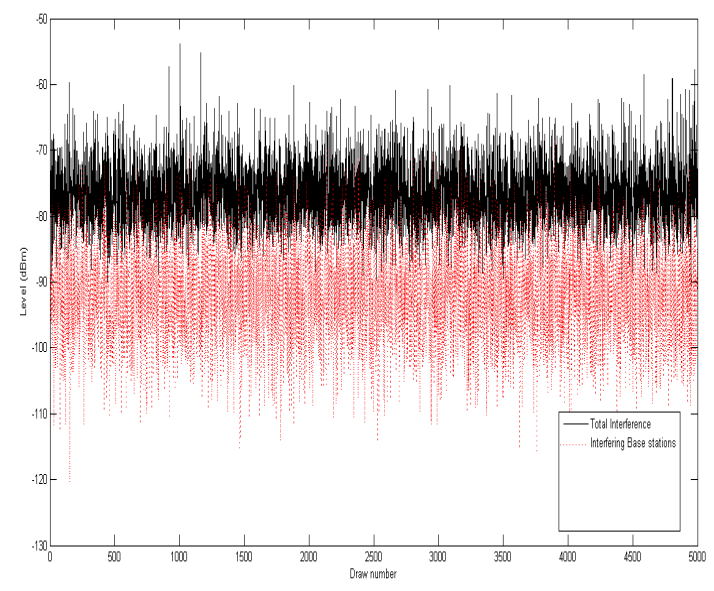

Fig. 7. Simulated total interference at Victim?s receiver

sites, i.e., Accra sites 1, 4 and 8 and Tema site 1 . The Received Total Wideband Power (RTWP) for the various sector antennas were measured with the IM2000 manager. The measurement set up is shown in Figure 8.

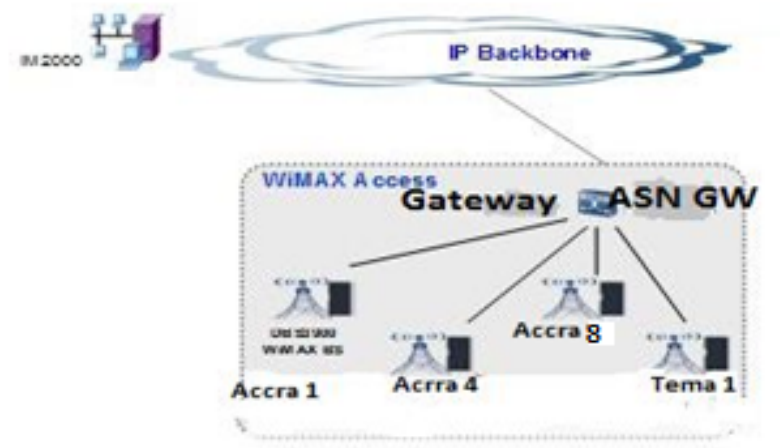

Fig. 8. RTWP measurement setup

The measured RTWP values at these four sites were very high and have been presented in Table 6 and Figures 9, 10, 11 and 12. Initially, the unacceptable high average values of $-86 \mathrm{dBm}$, $84 \mathrm{dBm},-80 \mathrm{dBm}$ and $-52 \mathrm{dBm}$ measured in Accra sites $1,4,8$ and Tema site 1 respectively which degraded network performance were attributed to equipment failures and wrong antenna configurations and as such it was necessary to carry out outdoor

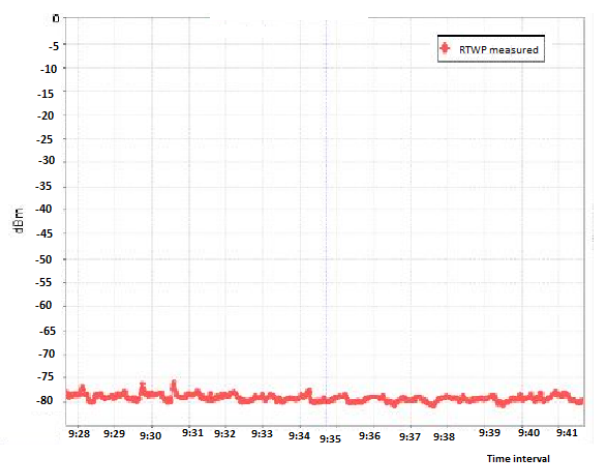

Fig. 9. RTWP measurements for Accra site 8

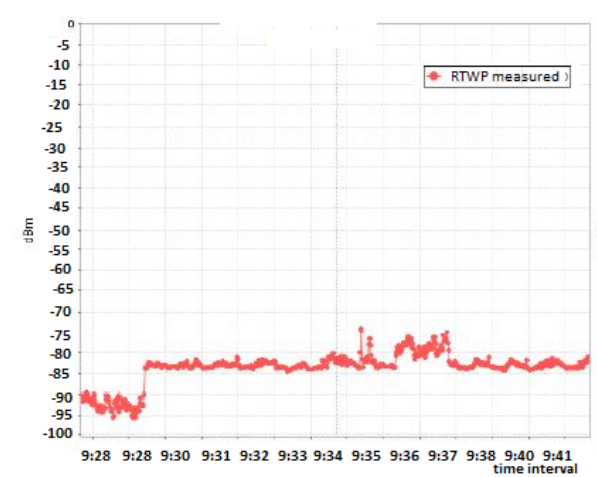

Fig. 10. RTWP measurements for Accra site 4

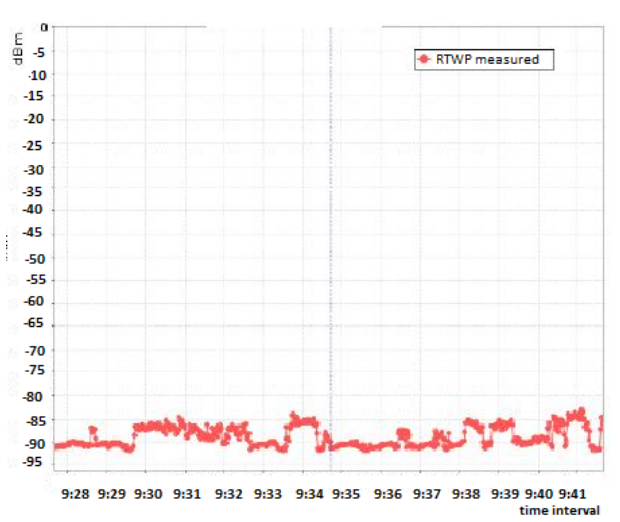

Fig. 11. RTWP measurements for Accra site 1

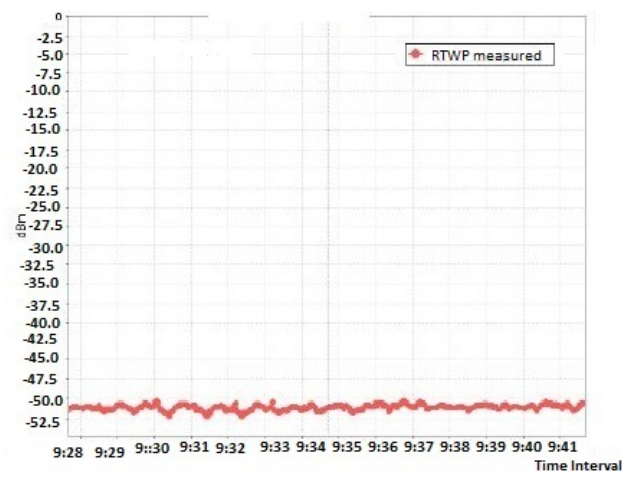

Fig. 12. RTWP measurements for Tema site 1

Table 6. RTWP measurement Results

\begin{tabular}{|l|l|l|l|l|}
\hline Site & Sector & $\begin{array}{l}\text { Min Mea- } \\
\text { sured } \\
\text { RTWP(dBm) }\end{array}$ & $\begin{array}{l}\text { Max Mea- } \\
\text { sured RTWP } \\
(\mathrm{dBm})\end{array}$ & $\begin{array}{l}\text { Average } \\
\text { RTWP } \\
(\mathrm{dBm})\end{array}$ \\
\hline Accra site 1 & Sector 1 & -93 & -83 & -86 \\
& Sector 2 & -93 & -82 & -86 \\
& Sector 3 & -90 & -85 & -85 \\
\hline Accra site 4 & Sector 1 & -96 & -74 & -83 \\
& Sector 2 & -95 & -76 & -85 \\
& Sector 3 & -96 & -76 & -84 \\
\hline Accra site 8 & Sector 1 & -90 & -75 & -82 \\
& Sector 2 & -89 & -76 & -80 \\
& Sector 3 & -90 & -76 & -79 \\
\hline Tema Site 1 & Sector 1 & -55 & -50 & -52 \\
& Sector 2 & -53 & -50 & -52 \\
& Sector 3 & -52 & -50 & -52 \\
\hline
\end{tabular}


measurement to determine the source of the Radio Frequency Interference (RFI).

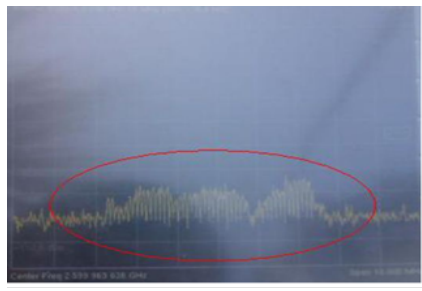

Outdoor interference Measurement for Accra site 4

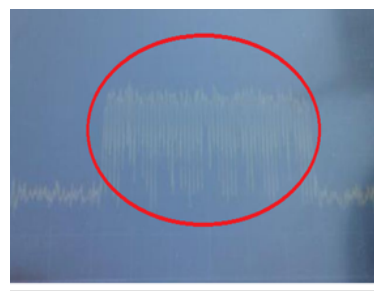

Outdoor interference Measurement for Tema site 1
Fig. 13.

Interference measurements were carried out at two sites, i.e. Accra site 4 and Tema site 1 and measurements through the WiMAX antenna showed $-86 \mathrm{dBm}$ and $-60 \mathrm{dBm}$ respectively, as shown in Figure 13. This confirmed to large extent the presence of external RFI to the antenna systems.

\subsection{Discussion Of Results}

The exceptionally high levels of RTWP measurements for the selected BS as presented in Table 6 and Figure 13 cannot be explained by regular interference caused by MS since this 4GWiMAX is a newly deployed network with very low traffic. This interference can be fairly attributed to the simulated mean interference value of $-76.5199 \mathrm{dBm}$ from nearby BS and other RFI sources.

Spectrum analyzer measurements as shown in Figure $13 \mathrm{did}$ show external interference sources. From the RTWP measurements that were carried out in the network, approximately $36 \%$ of cell sites were suffering from constant high RTWP levels and this affects overall network performance.

This problem could be solved by installing filter but in order to minimize the cost involved in installing new filters, it is recommended to deploy Femto and Pico-cells in buildings in order to reduce the overall transmit powers of the BS and improve overall signal quality.

\subsection{Conclusion}

In this paper, the results of an iteration-based simulation approach for the study of multiple interfering base stations in a deployed 4G-WiMAX in a typical Sub-Saharan African conditions have been presented. Monte Carlo simulations based on the multiple interfering signals from neighboring BS in the WiMAX network based in the city centers of Accra and Tema has been used to evaluate the total interference on a BS. Field trial measurement results at four selected sites which were most affected by interference have been presented.

The effects of bandwidth isolations have not been considered in this paper and will be looked at subsequently. The deployment of Femto and Pico cells are currently under way and as such there isn?t enough data available to show the improvement in the system. When more data are available, the interference and transmission characteristics and the effects these smaller cells with lower transmit powers, have on the overall WiMAX system performance will be properly discussed.

\section{REFERENCES}

[1] David Turahi. WSIS The Way Forward, 2013. [Online:www.kus.uu.se/pdf/publications/ICT/PostWSISDrTurahi, Accessed on 27/02/2013].

[2] E. A. Armah. Keynote address by deputy minister of information, ghana on the occasion of WTIS day,. [Online:http://www.nca.org.gh/ , Accessed on 20/02/2013], 2012.

[3] Selim Hossain, A. N. M. Enamul Kabir, and Debabrata Kumar Karmokar. Wire Type Multiband Strip Antenna for WiMAX /WLAN Operations. International Journal of Soft Computing and Engineering (IJSCE) ISSN, 1, Issue 5:22312307, November 2011.

[4] Xuemin Huang and Jijun Luo. Automatic Configuration and Optimization of WiMAX Networks. In published in WiMAX Network Planning and Optimization Yan Zhang ISBN: 9781-4200-6662-3.

[5] Jaroslav Holiš and Pavel Pechač. Simulation of UMTS Capacity and Quality of Coverage in Urban Macro- and Microcellular Environment. RADIOENGINEERING, 14(4):2126, December 2005.

[6] J Laiho, A Wacker, and T Novosad. Radio Network Planning and Optimization for UMTS. New York: John Wiley \& Sons, 2001.

[7] ECC Report 119. coexistence between mobile systems in the $2.6 \mathrm{GHz}$ frequency band at the FDD/TDD boundary. In Kristiansand, June 2008.

[8] WiMAX Forum. Managing TDD-FDD Interference between Co-Sited Base Stations deployed in Adjacent Frequency Blocks, 3rd November 2009.

[9] Jean-Philippe Kermoal. Introduction to SEAMCAT. [Online: http://www.seamcat.org/ , accessed: 28/02/2013], October 2010. European Communications Office document. 